\title{
MOVIMIENTO ESTUDIANTIL ANTIFRANQUISTA, CULTURA POLITICA Y TRANSICIÓN POLITICA A LA DEMOCRACIA
}

\author{
Alberto Carrillo-Linares
}

\section{INTRODUCCIÓN}

Resulta paradójico que exista un consenso más o menos generalizado sobre la importancia del movimiento estudiantil en la lucha contra la dictadura franquista y en la transición política a la democracia, pero que, por otro lado, no se hayan realizado apenas reflexiones en profundidad sobre tal relación efectuándose más bien enunciados axiomáticos que acaban por convertirse en afirmaciones tautológicas, en ocasiones creo que no del todo bien resueltas ${ }^{1}$. El relativo olvido de la lucha contra Franco en la Universidad está siendo solventado en los últimos años con el desarrollo de investigaciones centradas en la materia, generalmente de ámbito local aunque con frecuencia escasean las reflexiones teóricas ${ }^{2}$. Quiero decir, existen meritorios estudios sobre el movimiento estu-

1. Y esto es así tanto entre los historiadores como entre la opinión pública general. Sobre el primer colectivo baste con consultar cualquier obra actual centrada en la historia del franquismo; en relación con el segundo, véase, por ejemplo, el resultado de la encuesta realizada con motivo de los 25 años del inicio de la transición política a la democracia, base del artículo de AVILÉS FARRÉ, Juan, "Veinticinco años después: la memoria de la transición", Historia del Presente, n. ${ }^{\circ}$ 1, (2002), pp. 88-97, en particular, p. 91, donde se hace referencia a la contribución del movimiento estudiantil

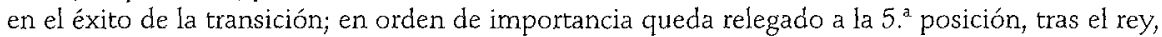
los ciudadanos en general, el movimiento obrero y los medios de comunicación. En el mismo número de dicha revista, Ramón García se refería a la "omisión» del movimiento estudiantil en la historiografía, junto con el movimiento campesino, aunque reconocía que "quizás por razones sentimentales, el movimiento estudiantil ha merecido una mayor atencion», pese a que distaba "de ser satisfactoria la atención prestada». GARCÍA PIÑERO, Ramón, "El obrero ya no tiene quien le escriba. La movilización social en el «tardofranquismo» a través de la historiografía más reciente», pp. 104-115 (las citas en pp. 112 y 115).

2. La bibliografía sobre el tema, incluyendo las crecientes comunicaciones en congresos - de muy variable calidad-está notando un buen reflujo. Desde la pionera obra de FArGA, Manuel Juan, 
diantil en varias universidades, dándose por supuesto que la conflictividad per se es la garantía de la lucha por la democracia, aunque no nos hemos detenido a explicar con precisión cuál es el aporte exacto del tal movimiento a dicho fenómeno de cambio, tanto en el terreno humano como en el de la cultura política. Algo más se ha reflexionado sobre la relación entre el movimiento estudiantil y los llamados nuevos movimientos sociales ${ }^{3}$.

Como decíamos, una primera circunstancia llama poderosamente la atención: la identificación inexcusable entre disentimiento y transición. La simple oposición no es argumento suficiente para reconocerle la aportación de cara a la transición puesto que pueden constituir dos realidades independientes: también

Universidad y democracia en España (30 años de lucha estudiantil), México, 1969, pasando por el clásico estudio de MARAVALI, José María, Dictadura y disentimiento politico. Obreros y estudiantes bajo el franquismo, Madrid, 1978 y el de GINER, Salvador, «Libertad y poder político en la Universidad española: el movimiento democrático bajo el franquismo", en PRESTON, Paul, España en crisis: evolución y decadencia del régimen de Franco, México, 1978, pp. 303-355, hasta la actualidad, se ha detectado una evolución positiva en el número de títulos, especialmente en los dos últimos lustros, una circunstancia que merecería algún estudio de cuantificación. Una catacterística es común a la mayoría (no todos) de los autores que se han centrado en el tema (ya desde la publicación de los números 1 y 2 de la revista Materiales en 1977): vivieron en primera persona, casi todos como militantes, el fenómeno que describen. Sin ánimo de ser exhaustivo $-y$ pido disculpas por esta extensa nota-, existen investigaciones para Canarias (DÉNIZ RAMíREZ, Francisco A., La protesta estudiantil: estudio sociológico e histórico de su evolución en Canarias, Madrid, [1999]), Valencia (SAnz DíAz, Benito y Rodríguez Bello, Ramón Ignacio (eds.), Memoria del antifranquismo. La Universidad de Valencia bajo el franquismo. 1939-1975, Valencia, 1999 y SANZ DÍAZ, Benito, Rojos $y$ demócratas. La oposición al franquismo en la Universidad de Valencia, 1939-1975, Valencia, 2002), Cataluña (COLOMER I CALSINA, Josep M., Els estudiants de Barcelona sota el franquisme, Barcelona, 1978, 2 vols.), Madrid (VALDELVIRA GONZÁlEZ, Gregorio, El movimiento estudiantil en la crisis del franquismo. La Universidad Complutense (1973-1976), Madrid, 1992 y ÁlVAREZ COBELAS, José, Envenenados de cuerpo y alma. La oposición universitaria al franquismo en Madrid (1939-1970), Madrid, 2004), Valencia (tesis doctoral de RODRIGUEz TEJADA, Sergio, Dictadura franquista y movimiento estudiantil en la Universidad de Valencia, 2005) o Sevilla (RUBIo MAYORAL Juan Luis, Disciplina y rebeldia. Los estudiantes en la Universidad de Sevilla, (1939-1970), Sevilla, Universidad, 2005), y mis propias investigaciones. A ello habría que sumarle las comunicaciones en diversos congresos y obras de carácter más general que aluden al tema, que se han referido a ámbitos locales del movimiento estudiantil (Cádiz, Cataluña, Galicia, Granada, Madrid, Málaga, Murcia, Sevilla, País Vasco, Valencia, Valladolid, etc.) o aspectos parciales (organizaciones, huelgas, fechas simbólicas, represión, sociología, etc.). Muy pocos autores han intentado realizar una historia general del movimiento estudiantil durante el franquismo (PALAZUELOS, Enrique, Movimiento estudiantil y democratización de la Universidad, Madrid, 1978; VALDELVIRA [GONZÁLEZ], Gregorio, La oposición estudiantil al franquismo, Madrid, 2000). Pese a las alusiones que, en éstos, se hacen a algunos distritos que no fueran Madrid y Barcelona, siguen siendo historias de dichas universidades y las conclusiones están muy condicionadas por la dinámica interna en las mismas. Así las cosas, creo que sigue quedando pendiente esta tarea a riesgo de acabar confundiendo la historia general del movimiento estudiantil español con la de los distritos madrileño y catalán.

3. Cfr. Ṕ́REZ LeDEsma, Manuel, «Cuando lleguen los días de la cólera»: movimientos sociales, teoría e historia", en VV. AA. Problemas actuales de la historia (Terceras Jornadas de Estudios Históricos), Salamanca, 1993, pp. 141-187, [publicado posteriormente en Zona Abierta, n. ${ }^{\circ} 69$, (1994), pp. 51120]; y del mismo autor: "Los nuevos movimientos sociales y la Historia del Tiempo Presente", en Díaz Barrado, Mario P. (coord.), Historia del Tiempo Presente. Teoría y metodología, Badajoz, 1998, pp. 63-77; así como "Nuevos" y "viejos" movimientos sociales en la transición", en MOLINERO, Carme (ed.), La transición, treinta años después, Barcelona, 2006, pp. 117-151. 
se opusieron organizaciones terroristas como ETA, GRAPO, FRAP, partidos políticos que abogaban por sistemas de partido único y cercenaban la libertad (MCE, ORT, PTE, PCE(M-L), LCR, PCE(R), falangistas disidentes nostálgicos de José Antonio y su pensamiento revolucionario, etc. Esto es, no hay una relación directa y necesaria entre oposición y transición política, tal y como se suele enunciar, puesto que había posiciones revolucionarias que en nada secundaban el cambio que se experimentaba, aunque hubieran tenido un papel fundamental en el desgaste estratégico del régimen dictatorial que hizo inviable su continui$\mathrm{dad}^{4}$. Pero de ningún modo esto supone una aportación concreta.

En el presente artículo intentaré esbozar un cuadro de análisis en el que tendré en cuenta tanto el marco general en el que se desenvolvió el movimiento estudiantil como algunas de las aportaciones concretas (en un doble sentido) que hizo de cara a la transición, sin perder de vista la cultura política de la que bebieron y, al tiempo, forjaron los estudiantes, una de las piedras claves en la transición, junto con su propio perfil social. En definitiva, la tesis básica que se defiende es la siguiente: el movimiento estudiantil fue un pilar cardinal de cara a la transición política y, me atrevería a decir más, en términos profundos, la transición se coció en la Universidad más que en ningún otro lugar ${ }^{5}$. Para entender esta afirmación en toda su dimensión, es preciso partir de un supuesto básico: antes de la transición política a la democracia existió una transición social que implicó una transformación profundísima de la cultura política, sin la que no hubiera sido posible, de ninguna manera, el proceso técnico que llevó de la dictadura a la democracia ${ }^{6}$.

Por lo tanto, el concepto teórico esencial sobre el que se sostuvo el cambio fue el de cultura politica que rompió de lleno con la construida, fomentada y que pretendía dejar en herencia el propio franquismo. Y esto es así, sobre todo a la vista de un hecho irrefutable: ningún movimiento social consiguió derribar directamente al régimen y Franco murió en la cama. El valor de dichos movimientos, por lo tanto, se halla en otro lugar. Así pues, me centraré en tres vectores,

4. Cito dos casos a modo de ejemplo que son suficientemente significativos: Consuelo Laiz parece entender que ETA conformaba un partido político semejante al PTE, LCR, ORT, etc., al incluirlo como tal en La Lucha final. Los partidos de la izquierda radical durante la transición española, Madrid, 1995. DEL ÁGUILA, Juan José, en El TOP. La represión de la libertad (1963-1977), Barcelona, 2001, acaba otorgando teóricamente - por no desagregar los datos- la misma categoría analítica a los miembros de las organizaciones terroristas procesados por el TOP que a los militantes de CC. OO., UGT, PCE, PSOE, activistas estudiantiles, manifestantes, etc., en su defensa de la libertad. El título de la obra y los epígrafes de la misma inducen inconscientemente a tal situación psicológica.

5. Evidentemente, esta afirmación, que pretende hacer las veces de titular periodístico, precisa de muchas matizaciones, comenzando porque habría que situarla en su justo término, lo que significa concretar la relación de fuerzas con otros movimientos sociales sin los que tampoco se concibe la transición, como el obrero, el vecinal, etc. Como en cualquier sistema complejo, ninguno se puede excluir para comprender el fenómeno resultante.

6. Para referinos a la fase abierta tras la muerte de Franco prefiero emplear la expresión transición política a la democracia. Por razones de brevedad, utilizaré el término transición a secas aunque teniendo siempre presente la tesis de que la transición en sentido general no comenzó el 20 de noviembre de 1975, fecha que marca, eso sí, un punto de inflexión en el marco de oportunidades políticas. 
con sus correspondientes ramificaciones, para concretar algunas de las relaciones que creo existieron entre movimiento estudiantil, cultura política y transición.

\section{LA RUPTURA GENERACIONAL}

Es un lugar común considerar el factor generacional como uno de los puntos destacados en la disidencia. Tan aceptada está la idea que han empezado a surgir algunas voces que consideran este hecho como resabido y que por lo tanto hay que buscar nuevas explicaciones. Opino que, por más que se diga, fue éste un hecho determinante y por lo tanto no puede el investigador abstraerse del mismo, por mury antigua que sea la idea. Se puede afirmar que, en términos generales, hubo una verdadera ruptura generacional en dos sentidos: por la edad y desde el punto de vista cultural, lo que acabó adoptando un matiz político de carácter subversivo; ambos son condicionantes de primer orden.

Cuando analizamos la oposición a la dictadura en general $-y$, obviamente la estudiantil-, se percibe con claridad que el mayor porcentaje de los participantes habían nacido después de la guerra civil, una contienda, por consiguiente, que conocían de oídas, pese a que hubieran podido padecer sus consecuencias. Para la Universidad, los márgenes cronológicos se podrían establecer entre 1945 y 1955 (1960, si incluimos la muy importante de bachillerato), pudiéndose hablar, con cierta propiedad de una especie de Generación de 1950, aún asumiendo los problemas que cualquier definición generacional entraña; es la zona de fechas de la que hablaba Ortega y Gasset. Se trata de una generación que se enfrenta a la anterior, marcada por un hecho (el franquismo) y que además desarrolló unos códigos de comunicación alternativos, incluido el lenguaje, construyendo un léxico que se acabó convirtiendo en un verdadero leit motiv de toda la generación. Volveré sobre este punto. Por otro lado, como en el concepto de generación literaria, la de la oposición universitaria estuvo sometida a una formación intelectual semejante que se tradujo en una verdadera crisis generacional; la configuración de todo el sistema de pensamiento (y de militancia) se apoyaba en una compleja red de relaciones personales (familiares, amorosas, contactos del barrio, el instituto o la universidad, centros culturales, etc.), de donde deriva la necesidad metodológica de análisis microhistóricos y reconstrucción de marcos de micromovilización, etc. Fue también frecuente la participación en actos colectivos propios, etc.

La importancia del hecho estriba en que con la pérdida de esta generación se hizo imposible la continuidad sociológica e histórica de la dictadura: la juventud representaba la continuidad y se perdió por el camino. Los supuestos proyectos despolitizadores elaborados por los capitostes del franquismo de cara a la desmovilización política de este sector social fracasaron de lleno: en realidad no se trataba de una despolitización, como se ha dicho, sino sencillamente de una politización en un sentido determinado, aquel que denigraba el libre juego parlamentario, considerado como esencialmente perverso ${ }^{7}$. Pero la juventud,

7. La concepción peyorativa de la política se mantuvo hasta los últimos días de la dictadura: "Los partidos políticos, para mí, son el opio del pueblo, y los políticos sus vampirosn, sentenció el general 
como había ocurrido en los años 30 , progresivamente volvió a convertirse en un verdadero agente político y de movilización de incalculable trascendencia.

Los adalides del franquismo no podían dejar de reflexionar sobre la importancia de la juventud en aras a la permanencia de un régimen considerado como eterno; la Universidad fue su talón de Aquiles. En buena medida el proceso de despolitización se debía garantizar en este espacio pero fue un rotundo fracaso ${ }^{8}$. En 1963 Jesús Medel recordaba sus palabras de diez años atrás, refiriéndose a esta generación que denominó la "promoción de los sin fusil»:

"El timón de nuestra sociedad futura debe estar basado en un 18 de julio permanente. Es importante el heroísmo de unos y el testimonio de otros; pero en la continuidad deben contar con amplitud los que hoy acuden a la Universidad, levantada en sus muros y espíritu con sangre mártir. Ellos harán la posible o probable guerra total contra el comunismo.

(...) La corredención y la continuidad de España tienen un sistema medular formado por los que hicisteis la guerra y los que la vimos; pero precisa un sistema muscular permanente y progresivo, que forjarán los que en estos días acuden a la Universidad por vez primera, sin fusil de verdad, ni de palo siquiera. A la entrada, o en los claustros, verán lápidas de Caídos. Nuestra fortaleza, y la de España, pueden radicar algún día en ellos ${ }^{9}$.

En una conferencia ofrecida en el Ateneo de Madrid, el 11 de marzo de 1963, apuntaba López Medel con toda la intención:

"Escuchaba a Garrido Falla la idea de cómo el técnico que está en paro o el ingeniero ocioso se suele dedicar temperamentalmente al montaje de piezas que se distrae en la composición, en la construcción; mientras que el abogado, o el intelectual ocioso, tiende a desmontar, a desentrañar. En una palabra, en un país (...) es más peligroso y da menos estabilidad la abundancia de profesionales liberales que la abundancia de técnicos. En una posible nueva ordenación de la Universidad, las Escuelas Superiores deberían decididamente incorporarse al ámbito y la responsabilidad universitaria. La juventud tendrá entonces caminos e interés por el mundo de la técnica que es el mundo de nuestro tiempo. Porque en ese mundo, con él, es como podrá erigirse ese mundo de justicia social y de salvación eterna que todo muchacho joven suele pensar para la España del futuro ${ }^{10}$.

Para los dirigentes políticos, la juventud constituía un bastión a preservar, entendido como un objetivo cuasi militar, dado que se trataba de una cuestión estratégica. Esta perspectiva hizo que no se pudiera-ni quisiera-analizar en toda la

García Rebull. Entrevista en Nuevo Diario, suplemento de 28-IV-1974. RODRIGUEz JIMÉNEZ, José Luis, Reaccionarios y golpistas. La extrema derecha en España: del tarlofranguismo a la consolidación de la democtacia (1967-1982), Madrid, 1994, pp. 169-170.

8. Sobre este punto es de obligada consulta RUIz CARNiCER, Miguel Ángel, El Sindicato Español Universitario (SEU), 1939-1965. La socialización politica de la juventud universitaria en el franquismo, Madrid, 1996.

9. LÓPEZ MEDEL, Jesús, Ejército y Universidad, Madrid, 1963, pp. 106-107. Y tampoco faltaba la cita del Caudillo: "Porque creo en la Juventud, estoy al frente de España:.

10. López MEDeL, Jesús, Política de jiventud en la España futura, Madrid, 1963, pp. 22-23. Los subrayados son del original. 
profundidad que el tema requería; en absoluto se trataba de un aspecto accidental o epidérmico, todo lo contrario: dadas las condiciones políticas existentes, el cambio social se estaba produciendo en la clandestinidad y lo que el régimen percibía en forma de subversión, muy particularmente en la Universidad, no era más que la punta del iceberg, un vértice que había que erradicar con cualquier medio, incluido un sistema de inteligencia, el Servicios Especial, luego SECED, origen del actual Centro Nacional de Inteligencia $(\mathrm{CNI})^{11}$. Para Carrero Blanco el problema de la juventud radicaba en que, a finales de los 60 ya no estaba encuadrada, interpretando, que los alborotadores no eran más que una pandilla de ateos, drogadictos y anarquistas, según el conocido análisis que hizo en el Congreso con motivo del estado de excepción decretado en enero de 1969 a raíz de la agitación universitaria. Debía ser cierto que había no creyentes, consumidores de drogas e incluso algunos ácratas, pero la explicación del Almirante confundía un hecho accidental con la causa del malestar. En cualquier caso, la cuestión de fondo que interesa sí era elocuente: el necesario control de la juventud. En el Informe político presentado al Consejo Nacional, el 1 de marzo de 1973, Carrero recalcó la urgencia del asunto, ante lo que consideraba una guerra declarada por el mundo:

«El artículo 21 de la Ley Orgánica del Estado señala entre los fines del Consejo Nacional el de "contribuir a la formación de la juventud española, en la fidelidad a los Principios del Movimiento Nacional, incorporando a las nuevas generaciones a la tarea colectiva". Esta es una cuestión de enorme trascendencia. El Gobierno pide al Consejo Nacional el estudio en profundidad de tan importante tema. (...) Respeto a la juventud, sí, pero no abandono de la misma a los impactos incontrolados y agobiantes que el mundo actual lanza sobre ella. La defensa de nuestra juventud de los embates que hoy se lanzan contra ella para corromperla moral y materialmente constituye nuestra más grave responsabilidad. El "dejar hacer", el encogerse de hombros ante esta situación, aceptando cómodamente las consecuencias de esta ofensiva que la juventud padece como "moda de los tiempos" puede que no sea una figura de delito en los Códigos humanos, pero sí lo es ante la conciencia de cualquier hombre honrado y desde luego ante el juicio de Dios» ${ }^{12}$.

El obispo de Canarias, José A. Infantes Florido, en unas reflexiones pastorales tituladas Universidad, Sociedad y bien común, insistió igualmente en la idea de que a la juventud se la había "dejado sola» y reprodujo las palabras de Girón de Velasco que había explicado su parecer sobre el origen del problema:

«[EI] tremendo abandono en que se ha dejado a la juventud, no se ha creado en ella ilusiones y se le ha puesto como terreno de nadie, a disposición de los primeros

11. Fue impulsado por orden de Carrero tras los sucesos del mayo francés, temeroso de que el fenómeno se contagiara en España. Sobre ello, vid. SAN MARTÍN, José Ignacio, A las órdenes de Carrero Blanco (de Castellana a El Aaiun), Barcelona, 1983, pp. 21, 27 y 46. Ya era significativo que el servicio estuviera adscrito y sirviera en principio al Ministerio de Educación y Ciencia. Véase también DIAZ FERNÁNDEZ, Antonio M., Los servicios de inteligencia españoles. Desde la guerra civil hasta el $14 M$. Historia de una transición, Madrid, 2005, pp. 138-179.

12. Archivo General de la Administración (AGA), Presidencia, Secretaría General del Movimiento, Secretaría Técnica, caja 18.595, p. 20. 


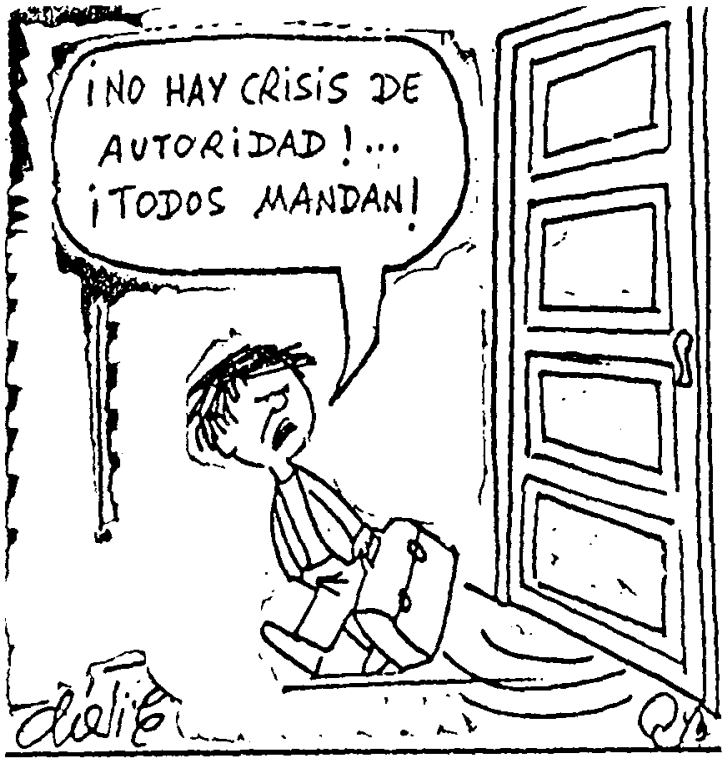

Imagen 1. Chiste sobre la Autoridad publicado en El Correo de Andalucía, 1-10-1972. que han querido mentalizarla, indefensa ante cualquier agresión política, a disposición de la subversión ${ }^{13}$.

Lo que no estaban dispuestos a aceptar los jerifaltes era que la pérdida de la juventud resultaba irreversible porque, fundamentalmente, se trataba de una pérdida existencial: creo que antes que política la ruptura definitiva con el franquismo fue cultural $y$ vital, de ahí la profundidad y complejidad del fenómeno. Las manifestaciones de este hecho se apreciaron por doquier: música, relaciones sexuales, hábitos, consumo, estilos y modas, etc. La crisis cultural del modelo impuesto por el régimen tenía que producir, obligatoriamente, la fractura política puesto que en esta instancia de actuación se trató de poner freno a un desarrollo natural de expresión y convivencia que, para más inri, adoptó una fachada underground ${ }^{14}$. Esta circunstancia hace que resulte obligado reconsiderar la clásica teoría de Spain is different, puesto que el franquismo nunca pudo aislar completamente al país lo que dio lugar a influencias constantes del exterior, en especial a partir de mediados de los sesenta. ${ }^{15}$ La ruptura cultural conllevaba la integración de unos nuevos valores que se enfrentaban políticamente con la dictadura, lo que llenaba de contenido la cultura política de una sociedad carente de libertad. Aunque fuera una crisis emocional e intuitiva, las consecuencias de orden político eran incuestionables, comenzando por la negación del concepto de Autoridad en el que tan firmemente se creía, máxime si tenemos en cuenta el origen del régimen (militar) y el modelo social que pretendía (de orden, apoyado en gente de orden, etc.).

13. A lo que Infantes añadió que tales palabras apuntaban «a toda la profunda dimensión del problema universitario». El discurso de Girón había sido pronunciado el 29 de octubre de 1972 y unos días más tarde citado por el prelado. Cfr. El Correo de Andalucía, 18-11-1972, p. 18.

14. Sobre los vínculos entre música underground y ruptura política, puede verse el excelente documental sobre el grupo Smash, que incluyó entrevistas a diversos personajes, algunos de los cuales con proyección política durante la transición. IGLESIAS, Gervasio (dir.), Underground, la Ciudad del Arco Iris, LZ Producciones, 2003.

15. Se ha señalado reiteradamente la importancia del turismo en esta apertura. Sin negar esta posibilidad, creo que se ha minusvalorado el papel de los medios de comunicación de masas en una sociedad ávida de información. Está por estudiar en profundidad esta relación. 
En definitiva, una generación que bebió y, al mismo tiempo, fue forjando una Cultura transgresora alternativa a la ofrecida por el franquismo $y$, dentro de ésta; una cultura política. La asimilación de esta cultura política por parte de la juventud fue un proceso relativamente rápido desde los años 60 , aunque de sedimentación progresiva, dados los diferentes estratos y variables que la integraban. Un elemento me interesa especialmente para el presente caso: el reclamo de la participación en las diferentes esperas de decisión (académica, política, etc.), lo que en la clásica obra de Almond y Verba se definió como cultura política participativa y que en la práctica supuso el paso de la delegativa a la participativa ${ }^{16}$. Paradójicamente, la participación en el SEU provocó un efecto no previsto o no deseado para el franquismo desde el momento en el que se pudo tomar conciencia de las deficiencias del sistema e iniciar el asalto definitivo al sindicato y proponer uno alternativo (Sindicato Democrático) que fuera controlado exclusivamente por los alumnos. Las infiltraciones de 1956 y la reacción de los seuistas nos aluden a lo temprano de la estrategia, incluso antes de que se produjera la ocupación de cargos promovida por CC.OO. para el mundo laboral (desde 1962). Dejar participar en un sistema viciado por su base pudo tener unas consecuencias más demoledoras que no permitir la participación, si es que esto hubiera sido posible, algo que dudo.

La asunción de una cultura política implica una relación emocional y racional muy particular con el contexto y la situación en la que tienen lugar los hechos objetivos, hasta el punto de que éstos pueden ser relativamente irrelevantes de cara a la respuesta de los grupos afectados puesto que la lectura y sensibilidad de los fenómenos se filtra a través de un complejo sistema de valores, símbolos, imágenes, metáforas, etc. que sirven para percibir e interpretar el mundo. Dicho en otros términos, lo importante es cómo se ve e interioriza el mundo, más que el mundo en sí: sin unos códigos valorativos, que pueden ser construcciones ideológicas o sentimentales, difícilmente se puede pasar a la acción, de ahí que para mover, primero haya que conmover, que es un proceso intelectivo ${ }^{17}$.

16. Me refiero, lógicamente a ALMOND, Gabriel A. y Verba, Sidney, La cultura civica. Estudio sobre

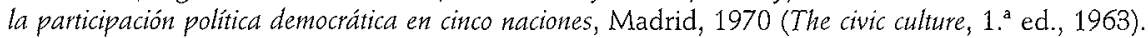
Las cinco naciones eran Alemania, EE. UU., Gran Bretaña, Italia y México. Cualquier definición de cultura politica integra en su seno muy diferentes aspectos: "actitudes, normas y creencias, compartidas más o menos ampliamente por los miembros de una determinada unidad social y que tienen como objeto fenómenos sociales", formando parte de ellos los "conocimientos", las "orientaciones", las "normas», el "lenguaje y los símbolos" (SANI, Giacomo, "Cultura política", en BOBBIO, Norberto; MatTeuCci, Incola y PASovino, Gianfranco (dir.), Diccionario de politica, Madrid, 1982, p. 415). O concebirla como «un sistema de referencias en el que se reconocen los miembros de una familia política, recuerdos históricos comunes, héroes consagrados, textos, simbolos, fiestas, vocabulario codificado", según BERNSTEIN, Serge, "L'Historien et la culture politique», Vingtième Siècle, n. ${ }^{\circ} 35,(1992)$, pp. 67 y ss. Del mismo autor puede consultarse: BERNSTEIN, Serge, Les cultures politiques en France, Paris, 1999.

17. En esta línea de trabajo se introducirían los análisis de los llamados procesos enmarcadores para comprender las acciones colectivas en forma de movimientos sociales. Sobre ello, cfr. McADAM, Doug; MCCARTHY, John D. y ZALD, Mayer N. (eds.), Movimientos sociales: perspectivas comparadas, Madrid, 1999, especialmente la última parte de la obra (pp. 369-496). Desde una perspectiva 


\section{Gráfico 1. Procesados por el TOP (1964-1976), clasificados por edades}

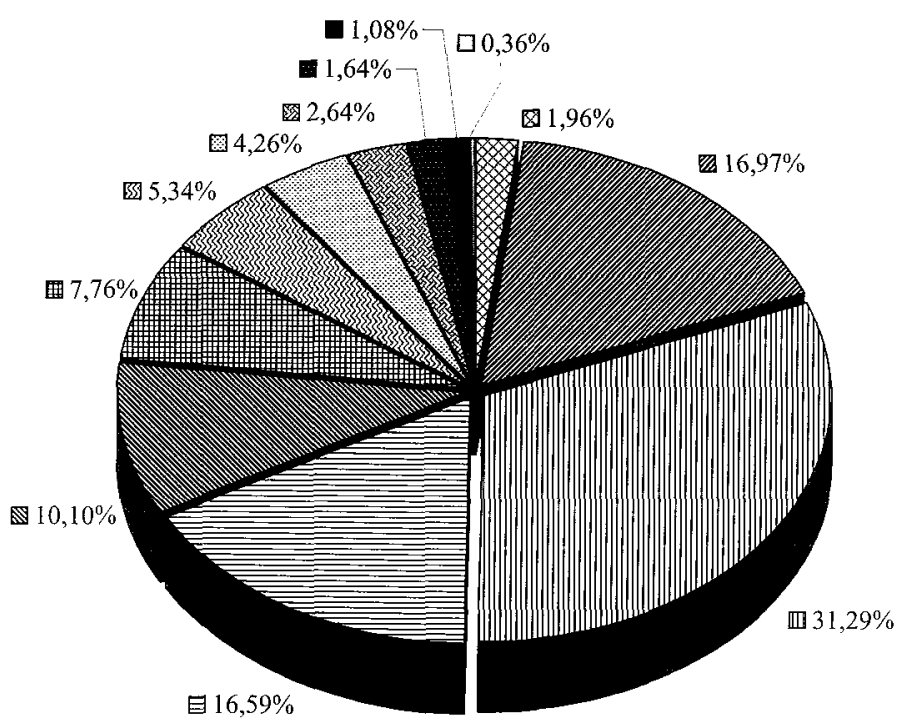

因 $16-17$

$\underline{\mathbb{1 8 - 2 0}}$

血 21-25

$26-30$

$31-35$

醩 $\underline{36-40}$

䍘 $41-45$

$\underline{46-50}$

$\underline{51-55}$

$\underline{56-60}$

Más de 60

No consta

Elaboración propia

Fuente: AGUILA, Juan José. El TOP .., p. 262.

En este sentido, el concepto de clima cultural adquiere especial relevancia para comprender la atmósfera en el que se insertan las protestas estudiantiles de los años $60^{18}$. Este cuadro general de análisis nos aporta algunos parámetros para

sociológica, también se ha analizado estos uprocesos simbólicos y cognitivos internos, que generan cambios en los marcos de acción colectiva y los modelos organizativos de los movimientos y en los cuales se construye el sentido de la participación». LARAÑA, Enrique, La construcción de los movimientos sociales, Madrid, 1999, pp. 21-22. En la misma vertiente de la construcción de la identidad: LARANA, Enrique y GUSFIELD, Joseph (eds.), Los nuevos movimientos sociales. De la ideología a la identidad, Madrid, 1994. También pueden consultarse diferentes capítulos de la obra colectiva IBARRA, Pedro y Tejerina, Benjamín (eds.), Los movimientos sociales. Transformaciones politicas y cambio cultural, Madrid, 1998, en particular el segundo bloque (pp. 111-215). Desde un ámbito teórico y metodológico: Casquete, Jesús, Política, cultura y movimientos sociales, Bilbao, 1998. El enfoque cultural de la protesta, en MANGINI, Shirley, Rojos y rebeldes, La cultura de la disidencia durante el franquismo, Barcelona, 1987.

18. Sobre este concepto y su proyección cíclica, vid. BRAND, Karl-Werner, "Aspectos cíclicos de los nuevos movimientos sociales: fase de crítica cultural y ciclos de movilización del nuevo radicalismo de clases medias", en DALTON, Russell J. y KUECHLER, Manfred, Los nuevos movimientos sociales, Valencia, 1992, pp. 45-69. El estudio de los «ciclos de protesta», centrado en la estructura de movilización y sus vínculos con las oportunidades políticas (aunque con alguna referencia a los marcos), puede verse en TARROW, Sidney, El poder en movimiento. Los movimientos sociales, la acción colectiva y la política, Madrid, 1997, en concreto pp. 263-286. 
comprender la dimensión de la contestación juvenil durante la dictadura, hasta el punto de que de los cuatro estados de excepción nacionales que hubo, al menos dos (1956 y 1969) lo fueron por causas directamente relacionadas con la agitación universitaria y en un tercero (Proceso de Burgos, 1970) el movimiento estudiantil tuvo una importante responsabilidad. Una sola muestra bastará para comprobar con exactitud la relación directa y necesaria entre oposición política y juventud: los datos de los procesados en el TOP durante sus años de existencia. En ellos, una circunstancia es poderosamente significativa: el $67 \%$ era menor de 31 años y el $77 \%$ no habían superado los 35 .

\section{MOVIMIENTO ESTUDIANTIL Y DINAMIZACIÓN SOCIAL}

A diferencia de lo que habitualmente se ha afirmado, especialmente desde la historiografía de combate, pienso que el estudiantil fue el movimiento social más importante durante el franquismo sesentón desde el punto de vista de la dinamización, y lo fue desde distintas perspectivas. En primer lugar por las movilizaciones y la agitación que pusieron en jaque a la dictadura, aunque nunca mate, eso sí. En este sentido, las acciones colectivas más trascendentes fueron las protagonizadas por los obreros y los universitarios, que jugaron un papel complementario, una especie de tándem en el que cada cual desarrolló su función: la importancia del movimiento obrero residía en su impacto económico y en la evidente puesta en entredicho del orden social ofrecido por el régimen que había servido, en última instancia, para justificar el golpe militar y el propio modelo político que nació de él, todo ello relacionado con la inexcusable referencia al problema del orden público ${ }^{19}$. Pero en este último apartado, el movimiento estudiantil tardofranquista fue el verdadero campeón, sin ningún género de dudas. Y ello tiene una explicación.

A las circunstancias generales propias de los dos movimientos (concentraciones naturales que favorecían la contestación, alta politización - no necesariamente partidista- de sectores claves en las movilizaciones, padecimiento y aprovechamiento de las consecuencias del desarrollo económico y la masificación, etc.), los universitarios contaban con una ventaja comparativa respecto a sus compañeros de protesta: las circunstancias sociales y personales que permitieron mantener un estado de crítica abierta casi permanente, con huelgas que se prolongaron durante varios meses $y$, en casos particulares -algunas asigna-

19. Entre otras investigaciones: SOTO CARMONA, Álvaro, Diversas interpretaciones sobre las causas y consecuencias de las huelgas en el franquismo (1963-1975), Barcelona, 1992; MOLINERO, Carme; YSÀS, Pere, Productores disciplinados y minorias subversivas. Clase obrera y conflictividad laboral en la España franquista, Madrid, 1998. Una óptica más amplia de los factores y formas de la descomposición de la dictadura en YSÀS, Pere, "La crisis de la dictadura franquista", en MOLINERO, Carme (ed.), op. cit, pp. 27-58 e YSȦS, Pere, Disidencia y subversión. La lucha del régimen franquista por su stupervivencia, 1960-1975, Barcelona, 2004. Una panorámica general, y ya clásica, sobre la conflictividad en los años sesenta: FUSI AIzPURÚA, Juan Pablo, "La reaparición de la conflictividad en la España de los sesenta", en FonTANA, Josep (ed.), España bajo el franquismo, Barcelona, 1986, pp. $160-169$. 
turas, profesores- durante años ${ }^{20}$. En el plazo inmediato, el régimen siempre temió mucho más la protesta obrera pero, en cierta medida, perdió de vista los efectos destructivos del otro movimiento, que fue mucho más corrosivo, del entramado profundo sobre el que se construye una sociedad.

La imposibilidad material de contención de lo que estaba ocurriendo en las universidades desde los 60 acabó siendo total, lo que a su vez provocó otro tipo de efectos, como las crisis más importantes en las élites de poder (políticas, académicas, gubernamentales y policiales). Éste es un hecho de especial importancia puesto que la ruptura en la cohesión de las minorías rectoras fue aprovechado por los contestatarios que percibieron grietas en el aparato de poder, lo que impulsaba o alentaba nuevos golpes de protesta y la búsqueda de aliados entre las élites que se deshacían ${ }^{21}$. De este modo, se podría decir que el movimiento estudiantil fue el que más desestabilizó el régimen y los pilares sobre los que se sostenía puesto que obligó a introducir un tema conflictivo de gran repercusión (el debate sobre sí mismo) lo que hizo que comenzaran a agravarse las diferencias y promover la toma de posiciones que pusieron en duda el régimen en su conjunto. Baste para ello la consulta de las actas de las Juntas de Facultad de las universidades donde desde 1965, al principio muy tímidamente, se fue gestando un clima de malestar sobre las medidas adoptadas por los diferentes ámbitos de decisión (sanciones administrativas, peticiones de certificados de buena conducta, expedientes disciplinarios, detenciones de estudiantes y profesores, etc.). El floreciente movimiento de los PNN (que en buena medida estaba capitaneado por profesores formados en la cultura política de la protesta de unos años antes), coadyuvó sobremanera en este sentido, aunque es posible detectar también intervenciones de numerarios y catedráticos. La incorporación de los alumnos a las Juntas como consecuencia de la aplicación de la LGE (1970) y los nuevos Estatutos, completó el panorama de crítica desde dentro ${ }^{22}$.

20. Escribo compañeros en cursiva por una razón: salvo casos excepcionales, durante las casi cuatro décadas que se mantuvo operativo el franquismo, estudiantes y obreros fueron colaboradores en un sentido genérico puesto que la solidaridad fue casi siempre unidireccional, de los estudiantes hacia los trabajadores y raramente a la inversa. La razón es obvia y tiene que ver con lo que apuntamos, amén de que puedan existir otras explicaciones circunscritas a la valoración profunda que ambos movimientos se tenían. Queda por hacer un estudio riguroso sobre las articulaciones reales y simbólicas entre estos dos movimientos, al margen de posibles afirmaciones generales sobre los objetivos compartidos.

21. Las alteraciones en las élites es una de las variables empleadas por los teóricos de los movimientos sociales (especialmente aquellos que tratan las oportunidades políticas) para comprobar su efecto en las transformaciones políticas. Cfr. MCADAM, Dough; MCCARTHY, John D. y ZALD, Mayer N., "Oportunidades, estructuras de movilización y procesos enmarcadores: hacia una perspectiva sintética y comparada de los movimientos sociales", pp. 32-33; McADAM, Dough, "Orígenes terminológicos, problemas actuales, futuras líneas de investigación", pp. 52-55 y passim; TARROW, Sidney, «Estado y oportunidades: la estructuración política de los movimientos sociales», pp. 71-99. Todas las referencias en MCADAM, Dough; McCARTHY, John D. y ZALD, Mayer N. (eds.), op. cit.

22. Esta circunstancia fue mucho menos frecuente en las Juntas de Gobierno, compuestas a partir de un sistema de filtrado más exquisito, lo cual no significa que no hubiera casos. La necesidad urgente de disponer de nuevos profesores, ante la avalancha de matriculados, hizo que resultara 


\section{Gráfico 2. Procesados por el TOP (1964-1976), clasificados por ocupación}

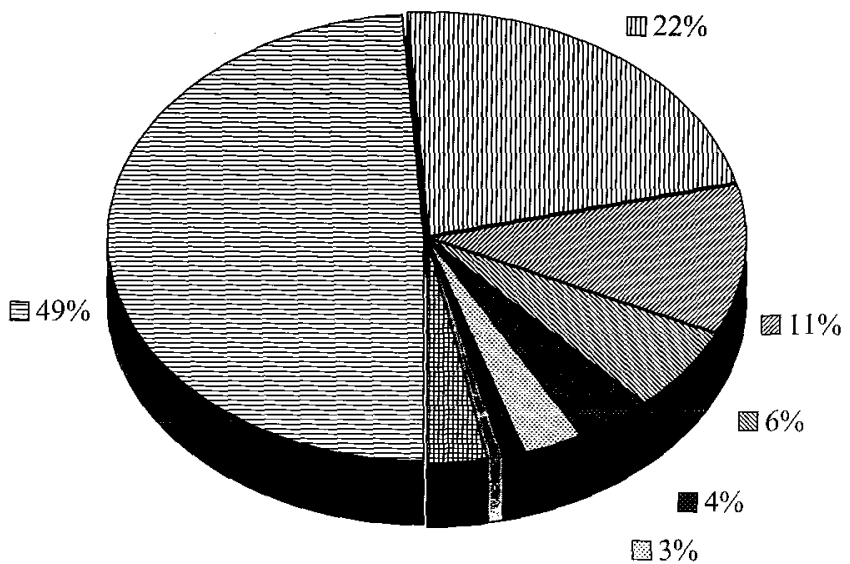

田 $3 \%$ $\square 1 \% \square 1 \%$
冒Obreros

面 Estudiantes

Administrativos

Técnicos Medios

Licenciados

Comerciantes

Religiosos

Artistas

Otros

Fuente: AGUILA, Juan José. El TOP ..., p. 278.

Las críticas cruzadas de unas autoridades a otras, alerta del grado de descomposición orgánica en el que se encontraba la dictadura, incapaz de activar un frente unido en la gestión o en la defensa de sus intereses. La reacción de la comunidad universitaria a las medidas de big stick adoptadas por el ministro de Educación, Julio Rodríguez, precipitaron los acontecimientos. El error juliano, con calendario académico incluido, dejó en evidencia los diversos intereses y perspectivas de la Universidad y los de las esferas políticas ${ }^{23}$. Por otro lado, la falla en las élites se detectó en ámbitos menos visibles pero de un calado incuestionable y afectaron nada menos que a la responsabilidad última sobre la movilización estudiantil. En una nota interna de la Brigada Social de Sevilla, se escribía:

"Los padres de los alumnos integrantes de esa llamada "mayoría silenciosa" no logran comprender por qué es tan difícil el problema de la Universidad y, en visión simplista, se preguntan cómo no son detenidos los instigadores de los desórdenes,

imposible la depuración por razones ideológicas, de ahí que fuera en las Juntas de Facultad donde se notaran los más importantes debates y, por consiguiente, las mayores fricciones.

23. La política de Julio Rodríguez, mano derecha de Carrero Blanco en la Universidad, se basaba fundamentalmente en actos de fuerza que dejaran constancia de quien tenía el poder: a la mano dura contra los agitadores profesionales sumó su desconcertante calendario académico con el que hacía comenzar el curso en enero. El asesinato de Carrero relegó al olvido al peculiar ministro. Su visión de las cosas -y defensa a ultranza de sus posiciones- quedó reflejada en RODRíguez MARTÍNEZ, Julio, Impresiones de un ministro de Carrero Blanco, Barcelona, 1974. 


\section{Gráfico 3. Detenidos durante el Estado de Excepción en España, por ocupación}

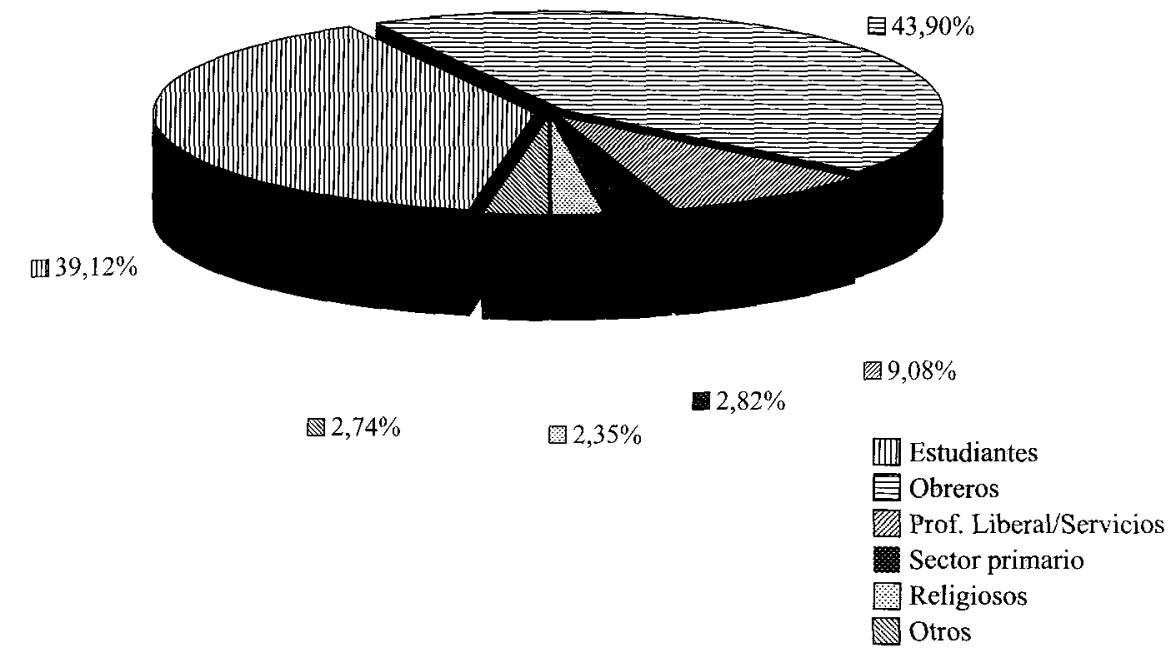

Elaboración propia.

Fuente: Boletín Informativo, Extraordinario, fascículo XI, 20-5-1969, pp. 445-446, 478-481.

cuyos nombres son públicamente conocidos y denunciados; evidentemente, tales detenciones originarían nuevas campañas y presiones y servirían de motivos de nuevas protestas.

(...) La propia Universidad, mediante sus Autoridades, sería la indicada, se estima en los sectores más sensatos de la opinión, para expulsarlos de su seno, no comprendiéndose cómo se permite la actuación de tales instigadores y su actividad se halla $\tan$ impune ${ }^{24}$

De lo que no cabe duda es de que la agitación estudiantil se encontraba en una situación personal óptima para la rebelión. Las cifras globales sobre los estudiantes procesados por $\mathrm{el}$ TOP confirman este hecho.

Aunque sobre estos datos hay que puntualizar algunas cuestiones técnicas (definición de obrero, puesto que no son lo mismo los trabajadores manuales que los de cuello blanco, etc.), sobre todo, para valorar la aportación proporcional del estudiantado hay que tener en cuenta un aspecto que relativiza la primera impresión: mientras que, en 1976, la población trabajadora superaba los 12,5 millones de personas, la estudiantil apenas sobrepasaba el medio millón en esta

24. Archivo General de la Jefatura Superior de Policía de Andalucía Occidental, leg. 2016, exp. 7. "Situación de la Universidad de Sevilla», 2. BRIS, n. ${ }^{\circ}$ 600.1, 27-II-1975. En similares términos recriminatorios se expresaba el Gobernador Civil de Sevilla. Cfr. Archivo General del Ministerio del Interior, sig. 4040. Memoria del Gobiemo Civil de Sevilla 1975, fol. 3. 


\section{Gráfico 4. Detenidos durante el Estado de Excepción en España, por provincias}

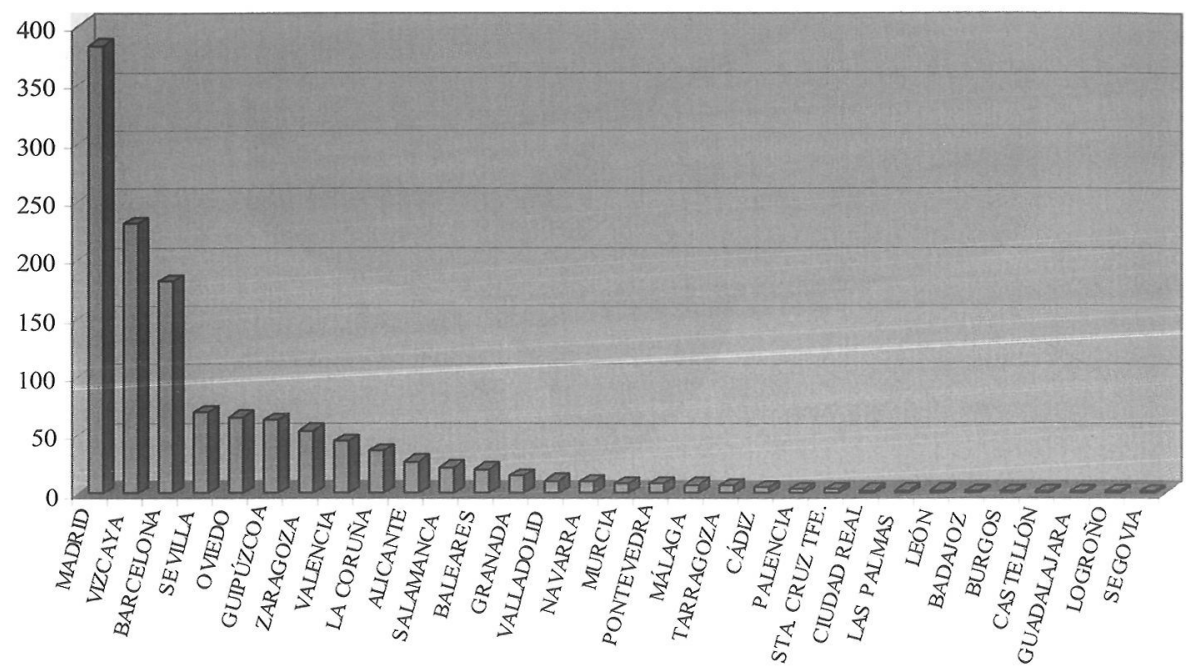

Elaboración propia.

Fuente: Boletín Informativo, Extraordinario, fascículo XI, 20-5-1969, pp. 445-446, 478-481.

fecha (cuando se inició la década de los 60, eran unos 180.000 en toda España) ${ }^{25}$. Estas cifras ponderadoras dan una idea más exacta y proporcional de lo que el fenómeno del movimiento estudiantil, supuso en la lucha contra la dictadura.

Con todo, para la policía el movimiento obrero seguía siendo su gran bestia negra y no desaprovechaba ninguna oportunidad para proceder a su represión. Los datos de los detenidos en España como consecuencia del Estado de excepción de 1969, cuyo detonante fue la agitación universitaria, son elocuentes sobre ello: aunque el objetivo primero era la contención del movimiento estudiantil, el obrero se llevó un buen zarpazo ${ }^{26}$.

Como se comprueba en el gráfico n..$^{\circ} 4$, el mayor impacto del Estado de excepción de 1969 se notó en Madrid, Vizcaya (represión del nacionalismo) y Barcelona, seguido a cierta distancia de Sevilla, Oviedo y Guipúzcoa ${ }^{27}$. Incluso en

25. Cfr. las estadísticas del Centro Económico y Social (CES), publicadas por TAMAMES, Ramón, La economía española, 1975-1995, Madrid, 1995, pp. 548-549; INE, Anuario de Estadistica Universitaria $1993 / 1994$.

26. En el gráfico n. 3 no se incluyen los detenidos que fueron puestos inmediatamente en libertad.

27. En Madrid, el 46,3\% de los detenidos fueron estudiantes, seguido del 35,5\% de militantes de CC.OO. (la clasificación es de la Brigada General de Investigación Social). Allí donde no había una agitación especialmente grave la policía se centró con grupos marginales, como en Alicante (27 detenidos) donde se cebaron con los Testigos de Jehová: los 20 apresados a nivel nacional, lo fueron en esta provincia. 
las acciones de cara al Primero de Mayo, una festividad eminentemente obreta, se comprueba la numerosa presencia estudiantil. Sirvan a modo de ejemplo, las estadísticas de los detenidos en España en la festividad de $1972^{28}$.

Además no sólo dicho movimiento fue el más dinámico por haber mantenido un nivel de contestación casi semanal (a veces diario) durante muchos años en casi todas las universidades, sino también desde el punto de vista cultural, por la incorporación de nuevos valores ideológicos y culturales, acordes con lo que posteriormente ocurriría: el aire de modernidad social y de refresco mental penetró, más que por ningún sitio, por la aulas universitarias, a veces incluso contra la moral de muchos de los partidos de la oposición, lo que nos alude a que el proceso iba más allá de lo puramente político. Muchas de las reivindicaciones sociales -que se leían en clave política- que realizaron los estudiantes de los años 60 y 70 , fueron satisfechas en la transición, una vez que los nuevos líderes, formados en aquella convulsa Universidad que enseñó a interiorizar y normalizar valores vinculados al mundo occidental, estuvieran en disposición de incorporarlos al bagaje de la transición (divorcio, aborto, despenalización del adulterio y relaciones sexuales en general, feminismo, estilos y modas, homosexualidad, etc.), rompiendo definitivamente con los valores decimonónicos heredados del franquismo. Lo cierto es que todos estos temas conflictivos fueron propuestos en los ambientes intelectualizantes vinculados con la Universidad (clubes culturales, conferencias, conciertos, etc.), nunca desde el ámbito obrero ni político, más preocupados por otras cuestiones ${ }^{29}$.

Esto a su vez tiene relación con otra realidad: fue en la Universidad donde más ebullición ideológica se vivió, probablemente por esa tendencia del estudiante a la reflexión en abstracto y a la conceptualización teórica -lo que llena de contenido la cultura política- disposiciones que resultan imposibles para los analfabetos o aquellos que se encuentran en un grado de ilustración limitado, caracterizados por la escasa capacidad de abstracción, una facultad que facilita la comprensión de sistemas políticos complejos que se basan en la cultura política participativa ${ }^{30}$. El Alma Máter favoreció esta capacidad, lo que podría explicar por qué la mayor parte de las organizaciones clandestinas que surgieron durante la dictadura lo hicieron en espacios universitarios o se nutrieron de estudiantes, mucho más que de obreros que se mantuvieron en las líneas clásicas del pensamiento, mientras que los aportes ideológicos más novedosos,

28. El $43,4 \%$ de los detenidos fueron estudiantes; el $48,9 \%$, trabajadores (incluidos empleados, administrativos, etc.); el 1,9\% abogados; el 1,6\% sacerdotes; el 1,3\%, funcionarios públicos y el $2,9 \%$, otros.

29. Sólo tardíamente, una vez comprobado el efecto de atracción que ciertos temas podían tener de cara a la militancia, los partidos y sindicatos los incorporaron a sus programas y estructuras (igualdad de género, medio ambiente, etc.).

30. No quiero decir con ello que los sistemas democráticos sean los propios y exclusivos de los países con altos índices de alfabetización, pero la proposición contraria me parece evidente: allá donde no hay una base de alfabetización suficiente, la democracia encuentra muchos más escollos en su consolidación. De esto fue consciente la II República, que trató de resolver el problema por los pies pero con la cabeza. 
especialmente de la extrema izquierda, si podían tener cabida en la Universidad (trostkistas, luxemburguistas, ácratas y espontaneístas, maoístas, etc.), por no hacer una relación de las mil siglas, algunas fantasmas, que brotaron de la nada y que se quedaron en la nada

En este sentido, la militancia política concreta de la oposición durante el franquismo respondió más a circunstancias accidentales que a otra cosa: redes de sociabilidad y familiares, compañeros de curso que captaban a los no iniciados, asistencia a conferencias, amigos del barrio, etc. De ahí algunos de los virajes ideológicos que se vivieron con posterioridad y que reubicaron a buena parte de los antiguos activistas. Este viaje explica igualmente cómo se pasó de una cultura política revolucionaria a una plenamente democrática.

Señalaría tres círculos concéntricos en el análisis de la militancia (y, por extensión, del propio movimiento estudiantil): 1.- El núcleo duro, organizado políticamente, adscrito a los partidos. Porcentualmente nunca debió superar el $5 \%$ de la población estudiantil. Funcionaban (con todos los peros que se quieran) como militantes de organizaciones clandestinas y representaban la vanguardia, generalmente con una actividad frenética ${ }^{32}$. 2.- Estudiantes que mantenían contactos políticos directos con los organizados y en ocasiones acababan militando, aunque no siempre. Colaboraban y estaban dispuestos a asumir riesgos personales más allá de las acciones colectivas. Representan los, tan frecuentes por entonces, compañeros de viaje de algunos partidos, aunque también puede haber filoanarquistas o espontaneistas que rechazan teóricamente

31. Sobre este universo radical, vid. LAIZ, Consuelo, op. cit.; HEINE, Harmut, «La contribución de la «nueva izquierda» al resurgir de la democracia española, 1957-1976», en FONTANA, Josep (ed.), op. cit., pp. 142-159; PORTUONDO, Ernesto, «Forja de rebeldes. Una aproximación a los orígenes de las vanguardias militantes del radicalismo de izquierdas en la segunda mitad de los sesenta: el movimiento estudiantil (1964-1970)»; RoCA, José Manuel. "Una aproximación sociológica, política e ideológica a la izquierda comunista revolucionaria en Españan, y de este último, "Reconstrucción histórica del nacimiento, evolución y declive de la izquierda comunista revolucionaria», los tres en ROCA, José Manuel (ed.), El proyecto radical. Auge y declive de la izquierda revolucionaria en España (1964-1992), Madrid, 1994, pp. 33-68, 69-89 y 91-122, respectivamente.

32. Los datos elaborados por mí para la Universidad de Sevilla (sobre la base de un millar de militantes, exactamente implicaban en torno a un 3,7\%) coinciden con los confeccionados por la Dirección General de Seguridad a nivel estatal, aunque con una puntualización. De los 251.000 estudiantes matriculados en toda España, calculaban que «sólo unos 10.000 forman parte como activistas y simpatizantes de las diferentes organizaciones clandestinas que operan dentro de la Universidad, lo que representa aproximadamente el $4 \%$ de la totalidad". Mis valoraciones se refieren exclusivamente a militantes, de manera que si incorporamos a los simpatizantes y compañeros de viaje el porcentaje aumentaría, aunque el concepto de simpatizante resulta un tanto difuso. Y si sumamos las personas que participaban en acciones puntuales (manifestaciones, huelgas, etc.), los datos aumentan sensiblemente. El interés del cuerpo de seguridad por reducir el impacto de la militancia era más o menos lógico y previsible. Cfr. Boletín Informativo de Actividades Estudiantiles, n. ${ }^{\circ} 4,2-4-1976$, p. 1. Justo dos años antes, cuando se estaba preparando el decreto de participación, la Secretaría Técnica de la Secretaría General del Movimiento, había elevado a un $5 \%$ el porcentaje de organizados en toda la Universidad, a los que agregaba otro $5 \%$ de "inquietos revolucionarios independientes", AGA, Presidencia, SGM, carp. "Estudiantes», subcarp. «Proyecto de Decreto por el que se regula provisionalmente la participación estudiantil a nivel universitatio", caja 18.791, "Informe sobre la participación universitaria", ff. [2-3]. 
las organizaciones. 3.- Aquellos que se suman a las acciones colectivas sin preocuparse por los posibles organizadores, asisten a manifestaciones, asambleas, actos culturales, concentraciones, etc. Éste es un espectro muy heterogéneo pues en el mismo se encontraban estudiantes con clara conciencia política y otros carentes de ella que, en cierta medida, se integraba y refugiaba en las acciones masivas. Incluso es posible detectar alumnos que rechazan cualquier imbricación de los partidos (falangistas disidentes, etc.). Las fronteras entre el grupo 2 y 3 pueden llegar a ser muy difusas. Es importante tener en cuenta esta clasificación porque en función de en qué grupo centremos nuestro estudio, la investigación sobre el movimiento estudiantil podría llevarnos a conclusiones muy diferentes, confundiendo el todo con la parte. Aunque sea factible la descomposición y análisis por aislado, en la práctica se dieron en una interacción constante; sólo considerándolo así se puede comprender en toda su dimensión dicho movimiento y sus particularidades.

\section{MOVIMIENTO ESTUDIANTIL Y EDUCACIÓN SOCIAL}

En el reparto de tareas que los movimientos sociales adoptaron -no estratégicamente-, desde mi perspectiva, el movimiento estudiantil fue el que mejor educó a la población de cara a la transición, no sólo desde el punto de vista político sino, fundamentalmente, cultural. En términos políticos, los más activos estudiantes miraron siempre hacia un movimiento obrero que debía ser su referencia: desde la teoría marxista el proletariado era el agente llamado a liderar el cambio en la historia; sólo las atrevidas tesis de Marcuse habían puesto en tela de juicio esta Verdad, pero su efecto sólo se notó en la superficie ${ }^{33}$. Así pues, en el universo mental de los estudiantes se introdujeron una serie de ideas que fueron exportadas al conjunto de la sociedad, con mayor o menor éxito.

La recepción de este nuevo movimiento social y de sus aportaciones por parte de la sociedad civil fue diferente a la de otros movimientos por varias razones: sus participantes eran hijos de las clases medias y, en buen porcentaje de los casos, hijos del régimen ${ }^{34}$. Por otro lado, también se benefició del hecho

33. Tanto es así que los primeros alumnos que se identificaron con Marcuse, muchos vinculados al PCE (I) -luego PTE-, no dudaron en proletarizarse para sentirse verdaderamente como los trabajadores, única realidad material que les podría llevar a pensar como ellos. No hay que descuidar que este curioso fenómeno respondía a la necesidad que tenían ciertos partidos obreros, nutridos de universitarios, de contar en sus filas con trabajadores y, a ser posible, manuales.

34. De unas sesenta entrevistas realizadas a estudiantes que participaron en el movimiento estudiantil, aproximadamente el $90 \%$ procedían de clases medias-altas, en ocasiones con cargos dentro del mismo régimen, e identificadas con la dictadura. Generalmente las fuentes orales son condescendientes con sus progenitores y los clasifican como franquistas sociológicos, rara vez como franquistas a secas. En este sentido se expresó un entrevistado cuyo padre había remitido en los años setenta una carta al rectorado para evitar el expediente a su hijo, incluyendo su currículum personal en el que hacía constar su "patriotismo" y algunos de sus méritos entre los que destacaba el haber tomado parte activa "en la represión de los sucesos de octubre de 1934", su participación directa desde el principio de la «Cruzada Nacional», el haber ingresado posteriormente en la División Azul, "siendo distinguido con algunas cruces y propuesto para la Cruz de Hierro del Ejército 


\section{Gráfico 5. Clasificación por ocupación de los parlamentarios en las Cortes Constituyentes (1977)}
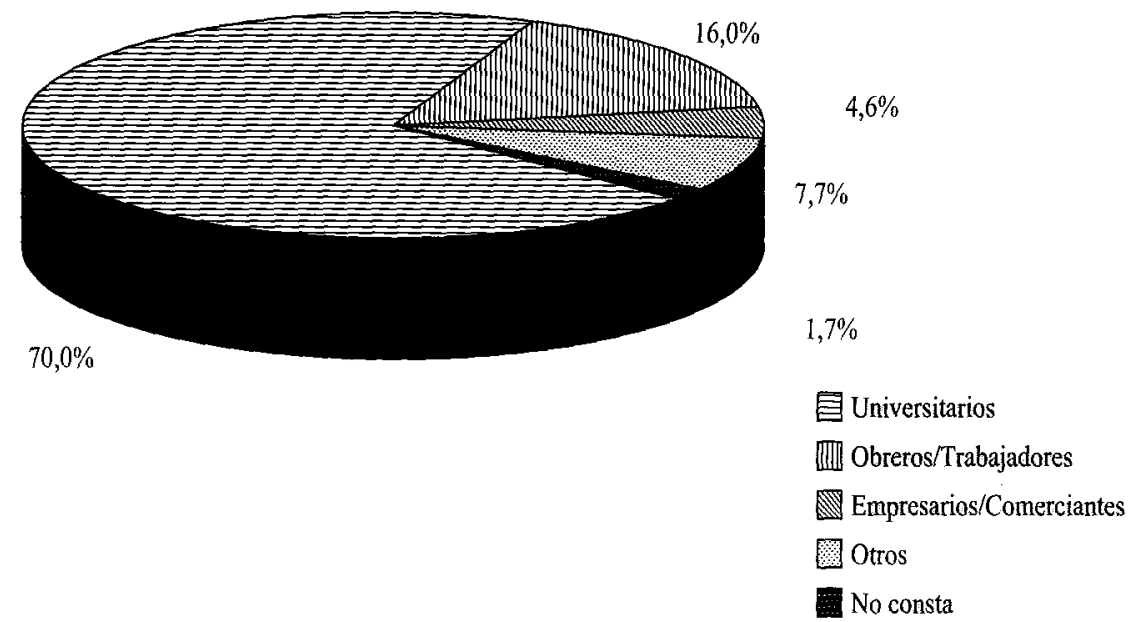

Elaboración propia.

Fuente: Base de Datos del Congreso de los Diputados.

de que el universitario era un movimiento no tan manchado como el obrero que contaba con una larga historia en su haber y un pasado cargado de actuaciones políticas revolucionarias que recordaban en exceso a la II República y a la guerra civil; lo cual no fue óbice para que hubiera constantes muestras de solidaridad con los trabajadores. Por el contrario, en las reivindicaciones y en la propaganda estudiantil apenas hay referencias a la República ni a la guerra, es un movimiento que mira hacia delante y se imbuye de algunas fuentes de inspiración propias de la modernidad, aunque en su faceta política pueda llegar a contener elementos del pasado; se afana en la defensa de paradigmas sociales novedosos, lo que lo enlaza con los llamados nuevos movimientos sociales ${ }^{35}$. La sensibilidad hacia los

Alemán», etc. Evidentemente, como todas las fuentes, las orales también hay que filtrarlas, en ningún caso evitarlas.

35. Habría que realizar muchas matizaciones sobre la integración del movimiento estudiantil dentro de los nuevos movimientos sociales (NMS), pues en numerosos aspectos se separa radicalmente de lo que se entiende por tales, especialmente en el núcleo de militantes asociado a los partidos políticos y las consecuencias que ello trae (jerarquización, institucionalización del movimiento, burocratización, etc.). Sobre los NMS, vid. DALTON, Russell J. y KUECHLER, Manfred, op. cit.; OFFE, Claus, Partidos políticos y nuevos movimientos sociales, Madrid, 1992; LARAÑA, Enrique y GUSFIELD, Joseph (eds.), op. cit.; DURÁN MUÑOZ, Rafael, "La literatura sobre los nuevos movimientos sociales. Una revisión", Revista de Estudios Políticos, n. ${ }^{\circ} 89$, (julio-septiembre 1995), pp. 369-401. Algunas críticas a la inclusión del movimiento estudiantil en los NMS pueden verse en las referencias bibliográficas de PÉREZ LEDESMA citadas más arriba; para la defensa, cfr. ARAN- 
estudiantes era distinta, lo que explica las numerosas muestras de apoyo que recibieron desde los años 60.

En otro orden de cosas, la Universidad educó y formó en sentido profesional y humano a los cuadros técnicos y políticos que abanderaron, desde los despachos, la transición: su formación universitaria -adquirida en unos centros donde la actividad política se había elevado a la categoría de normal y donde se habían normalizado algunos valores considerados por los sectores más ligados al pasado como subversivos-, no pudo ser un factor aislado del resto de la realidad que les circunscribía. De facto, fueron uno de los vasos comunicantes que dotaron de contenido social a la transición: por ejemplo, la incorporación de la mujer a la política se produjo por la vía universitaria. La fuerte movilización en la Universidad dejó huellas que marcarían el decurso del cambio político; el peso del perfil universitario en las diversas Cortes de la transición refuerza esta idea ${ }^{36}$. El segundo intento democrático en el siglo XX español contaba con unos protagonistas en las instituciones $y$ una sociedad con unos perfiles muy diferentes a los de cuarenta años atrás ${ }^{37}$.

En definitiva, en la Universidad se crea o difunde una cultura alternativa que llenó de contenido algunos espacios fundamentales en la construcción del nuevo régimen político cuyo funcionamiento no se basa sólo en los mecanismos formales (elecciones, partidos, etc.), sino en un conjunto de valores. La construcción de este universo paralelo conllevó la formulación de un lenguaje alternativo que debería reflejar la nueva existencia en tanto que el lenguaje es una representación del mundo, si se quiere, un mapa de la realidad (isomorfismo). De este modo los habitantes de ese mundo se sentían integrados e identificados en un proyecto colectivo que, en ocasiones, adquirió formas disruptivas. De ahí el empleo sistemático de términos que aluden a ideas asociadas a la democracia, participación, derechos y deberes, responsabilidad, etc. Fue frecuente la utilización de acrónimos y siglas (SDEU, RCP, RGU, PNN, etc.) que junto con las de los partidos políticos otorgaban una particular fisonomía a las universidades ${ }^{38}$. Todo aquello no fue más que una escuela de aprendizaje político y de valores

DA SÁNCHEZ, José María, "El movimiento estudiantil y la teoría de los movimientos sociales", Convergencia. Revista de Ciencias Sociales, n. ${ }^{\circ} 21$, (enero-abril 2000), pp. 225-250.

36. Por "Universitarios» se entiende aquellos que pasaron y se formaron en la Universidad, independientemente del lugar en el que desarrollaran su actividad profesional, es decir, los que tenían formación universitaria. Estos datos representan los mínimos puesto que hay casos dudosos que no se han integrado y se optó por incluirlos en obreros/trabajadores (periodistas, etc.).

37. Sobre la conexión entre las variables juventud-actitud democrática y niveles de formaciónactitud democrática, vid. MARAVALL, José M. ${ }^{2}$ y SANTAMARÍA, Julián, "Crisis del franquismo, transición política y consolidación de la democracia en Españan, Sistema, n. ${ }^{\circ} 68-69,(1985)$, pp. 79-129, en particular, las gráficas elaboradas a partir de datos del CIS (p. 90).

38. Además, la creación de este lenguaje particular y codificado, sirvió para dar idea de continuidad y organización al movimiento al reconocerse simbólicamente órganos, reuniones, plataformas, organizaciones, etc.: desde las Reuniones Coordinadoras Nacionales ( $\mathrm{RCN}$ ), que ya fueron numeradas por los estudiantes, hasta la recuperación 10 años después del Sindicato Democrático en 1976 (SDEU), pasando por las Reuniones Coordinadoras y Preparatorias del Congreso Democrático de Estudiantes (RCP del CDE) (años 1966-1968), etc. El que hemos llamado núcleo 
cívicos que los más jóvenes proyectaron sobre el conjunto de la sociedad, incluidos los hermanos menores ${ }^{39}$.

Aquel caldo de cultivo del que se alimentó la transición estaba condicionado por las influencias que procedían del exterior. Desde los años 60 el franquismo no pudo levantar tabiques de contención de los vientos que venían de fuera: el desarrollo económico, las posibilidades de salir al exterior, el contacto con el turismo, el consumo de los mass media, los contactos orgánicos de algunos partidos y asociaciones, etc. fueron también minando poco a poco al flebítico régimen político; un efecto perverso -como lo fue la participación en el SEU y otros tantos casos- que hizo inviable la continuidad de la dictadura ${ }^{40}$. Si nos ceñimos al movimiento estudiantil, las relaciones con el exterior fueron de diversos tipos, pero fundamentalmente dos: viajes y vínculos personales con estudiantes de otras universidades, y contactos orgánicos ${ }^{41}$. En este sentido, resulta obligado insertar al movimiento estudiantil español en el marco de las protestas juveniles de los años $60^{42}$. De estas influencias no sólo se tomaban formas de acción de protesta (estructuras de la movilización) sino también ideas y formas

duro siempre tuvo tendencia hacia la institucionalización del movimiento, mientras que el sector más heterogéneo tendía hacia las formas flexibles.

39. Fue un lugar común, según he podido comprobar, que la politización se heredara de hermanos mayores a los más pequeños con lo que la red de conciencia política se extendía aún más. Muchas veces, en el proceso de creación de la identidad, los más jóvenes asumieron posiciones más radicales que sus hermanos mayores.

40. Sobre el concepto de efectos perversos, cfr. BOUDON, Raymond, The Unintended consequences of social action, Londres, 1982. Su aportación a la idea de efectos perversos o no deseados se enmarcaba en las consecuencias no previstas (destrucción de oportunidades políticas) en relación con la actividad de los movimientos sociales. Lo definía como uaquellas situaciones en que un agregado de acciones individuales produce resultados colectivos que ninguno de los participantes habia propuesto o se habia imaginado".

41. Del interés que existía en esta materia da cuenta la creación, ya en 1966, dentro del Sindicato Democrático, de un Departamento de Prensa y Relaciones Internacionales. Entrevista a Mariona Petit Vilá (1-8-2006). Archivo privado Rafael Senra Biedma y Mariona Petit Vilá. Anteriormente hubo contactos con los dos grandes sindicatos internacionales, la UIE (Praga) y la CIE (Leiden), o nacionales, como la UNEF (Francia). Por esta vía se tuvo conocimiento directo, por ejemplo, del mayo francés. De estos acontecimientos se dispusieron de textos casi simultáneamente a que se distribuyeran en el país galo. Prueba de ello es la edición que realizó el Departamento de Información la Facultad de CCPPEE del Sindicato Democrático de la Universidad de Madrid del artículo de la Unión Nacional de Estudiantes Franceses (UNEF); Movimiento 22 de Marzo; Comité de Acción de los Liceos (CAL), "¿Por qué luchamos?", aparecido en Acción, n. ${ }^{\circ}$ 1, París, 7-V-1968. Puede consultarse, entre otros sitios, en el Archivo Central del Ministerio de Educación y Cultura, leg. 93.507.

42. Algunas obras de época se refirieron ya a los movimientos estudiantiles a nivel mundial en aquellos años. Entre otras, podrían señalarse: NiETO, Alejandro, La ideología revolucionaria de los estudiantes europeos, Barcelona, 1972; GÓMEZ PÉREZ, Rafael, La generación de la protesta: sentido y evolución de la crisis universitaria, Madrid, [1969]; GARRIGÓ, Andrés, La rebeldia universitaria, Madrid, 1970. 


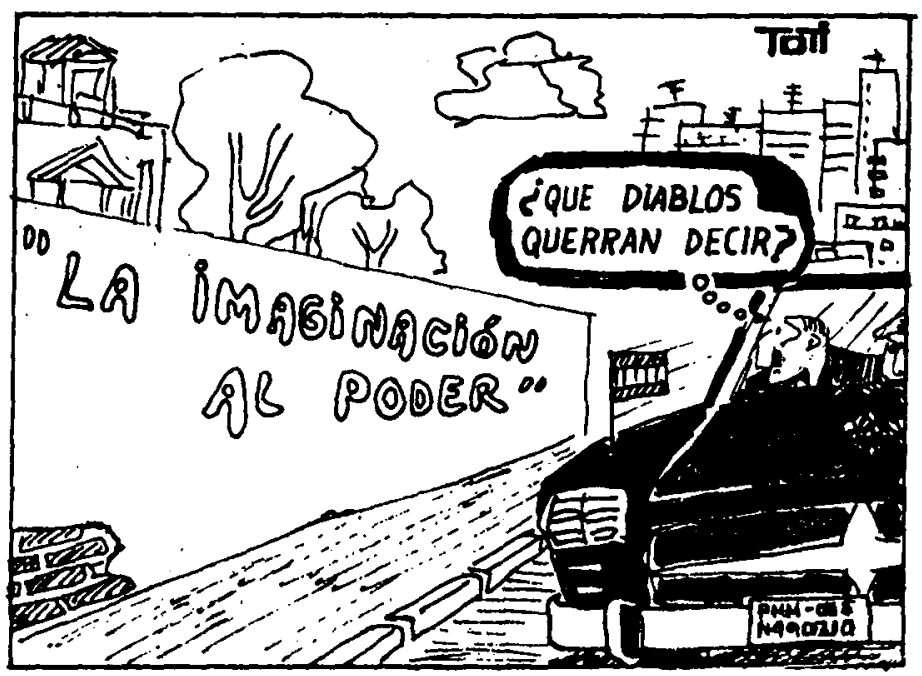

Imagen 2. Las diferencias entre dos generaciones a través del humor gráfico. El Correo de Andalucia, 9-2-1975.

de pensamiento que aportaron un marco teórico y sentimental que empararon a buena parte de una generación ${ }^{43}$.

\section{CONCLUSIONES}

El movimiento estudiantil, junto con otros movimientos sociales, especialmente el obrero, llevó a cabo un fuerte desgaste de la dictadura. En parte por la acción de los partidos políticos con presencia en la Universidad y en parte por la dinámica propia, la politización absoluta de la misma hizo que fuera un espacio incontrolable para las autoridades. La existencia de un falaz sistema de representación despertó pronto la conciencia política de los estudiantes y la incapacidad del franquismo para satisfacer las reivindicaciones planteadas y su tendencia a la represión configuró un panorama desalentador para los alumnos. El sórdido clima cultural y social que proponía la dictadura a unos jóvenes ansiosos de descubrir, hizo el resto: vital o existencialmente se estaba contra el franquismo. El paso político era inevitable y la Universidad se convirtió en un muy importante conejo de indias de la democracia ${ }^{44}$. Factores generacionales y culturales, reforzados políticamente, dibujaron un mapa que resultaba indomable para los más bunkerizados que hubieron de ver cómo los jóvenes, muchos

43. Sobre los préstamos de los movimientos sociales y los análisis transnacionales de éstos, vid. MARKOF, John, Olas de democracia. Mowimientos sociales y cambio político, Madrid, 1998, pp. $52-58$.

44. En estos mismos términos se expresó ya un editorial do Gaceta Universitaria: "La Universidad, conejo de Indias de la libertad", Gaceta Universitaria, n. ${ }^{\circ} 74,(15-2-1967)$, p. 3. 
con formación universitaria y con valores democráticos, les ganaban la partida sin romper la legalidad. De este modo se pudo romper con el franquismo institucionalizado: la tarea de zapa y formación en una cultura política alternativa tuvo finalmente su efecto en aquella generación llamada a sustituir a las viejas élites. 